\title{
Assessment of Venous Thromboembolism Risk and Adequacy of Prophylaxis in Selected Acute Care Medical Centres in Arabian Gulf States: Results from the ENDORSE Study
}

\author{
Faisal Alsayegh ${ }^{a}$ Hassan Kamaliddin $^{b}$ Eman Sheshah $^{d}$ Nasir Bukhamseen ${ }^{d}$ \\ Tarig Alkhuwaitire Ashraf Elhoufic \\ ${ }^{a}$ Department of Medicine, Faculty of Medicine, Kuwait University, Jabriya, Kuwait; ${ }^{b}$ Trauma ICU, Rashid Hospital,

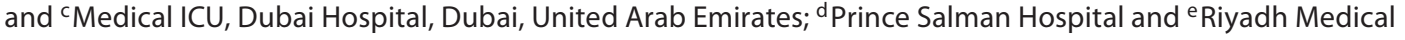 \\ Complex, Riyadh, Saudi Arabia
}

\section{Key Words}

Arabian Gulf · Thromboembolism • Prophylaxis · ENDORSE study $\cdot$ Kuwait $\cdot$ Saudi Arabia $\cdot$ United Arab Emirates

\begin{abstract}
Objectives: To assess the prevalence of venous thromboembolism (VTE) risk in acutely ill surgical and medical patients in selected acute care centres in the Arabian Gulf States, and to determine the proportion of at-risk patients who received effective prophylaxis in accordance with 2004 American College of Chest Physicians (ACCP) guidelines. Materials and Methods: Eight hospitals from 3 countries (Kuwait, Kingdom of Saudi Arabia, and United Arab Emirates) contributed to the global ENDORSE (Epidemiological International Day for the Evaluation of Patients at Risk for Venous Thromboembolism in the Acute Hospital Care Setting) study. Medical records were reviewed for all the in-patients aged $\geq 40$ years admitted to medical wards, and in patients aged $\geq 18$ admitted to surgical wards. The VTE risk and recommended prophylaxis were assessed according to the 2004 ACCP guidelines. Results: Of 1,291 evaluable patients, 801 were considered at risk of VTE; 391 (48.8\%) surgical patients and 410 (51.2\%) medical patients. Of the 801 patients, $322(40.2 \%)$ received ACCP-recommended VTE prophylaxis; 159 (40.7\%) of
\end{abstract}

surgical patients and 163 (39.8\%) of medical patients. Conclusions: The data showed that VTE prophylaxis was underutilized in high-risk hospitalized patients. We recommend that active measures should be implemented in acute care centres in these Arabian Gulf countries to ensure identification of patients at risk of VTE and institute the appropriate prophylaxis.

Copyright $\odot 2012$ S. Karger AG, Basel

\section{Introduction}

Venous thromboembolism (VTE) prophylaxis in acute care medical centres has been proven to be effective in reducing the rate of VTE in high-risk patients $[1,2]$. Several post-mortem studies have shown a significant hospital VTE-related mortality up to $10 \%$, thereby making VTE one of the main causes of death in hospitalized patients [3-5]. Awareness of potential risk factors that put hospitalized patients at risk of VTE and implementation of evidence-based thromboprophylactic measures in these patients have been published in several guidelines [6-10]. Despite the publication of these guidelines, some of them updated annually, a large number of practicing physicians and surgeons still underestimate VTE risk and 
thus implement inadequate VTE prophylaxis practices [11-13].

The ENDORSE (Epidemiologic International Day for the Evaluation of Patients at Risk of Venous Thrombosis in the Acute Hospital Care Setting) study was the first published global multicentre cross-sectional study that explored the percentage of acute care hospitalized patients at risk of VTE at any given time. It also looked into adherence to strict VTE prophylaxis practices according to risk stratification in surgical and medical patients as published in the American College of Chest Physicians (ACCP) guidelines [14].

The need to explore VTE risk estimation and adequacy of VTE prophylactic strategies in Arabian Gulf countries is of great importance since data in this area are rare. There is only one such study [15], which explored VTE risk factors, its rate in surgical and medical wards and the appropriateness of using pharmacologic anticoagulation. This study showed a significant VTE rate in both surgical and medical patients. In addition, there was inappropriate utilization of pharmacologic anticoagulants in patients with established VTE [15].

The objectives of this study were to use the global ENDORSE study to determine the prevalence of patients at VTE risk in selected acute care hospital settings in the Arabian Gulf region; to find the proportion of patients at VTE risk that received thromboprophylaxis in accordance with ACCP 2004 guidelines [7].

\section{Materials and Methods}

The methodology of the study has been described in the global ENDORSE publication [14]. Briefly, hospital selection was done randomly from authoritative lists of acute care centres in 3 Arabian Gulf countries: Kuwait, Kingdom of Saudi Arabia (KSA) and United Arab Emirates (UAE). Hospitals with more than 50 beds that admit patients with acute and chronic medical disorders as well as scheduling routine surgical procedures were considered eligible for inclusion in the study. Approval of the local hospital authorities was obtained before collecting the data. Signed patient consent was not required.

Patients' data, including demographics, diagnosis on admission, VTE risk factors, factors associated with risk of bleeding, duration of hospital stay and VTE prophylaxis used including the dosage (in accordance with ACCP guidelines), were extracted from the patients' medical records. Standardized case report forms were used by trained medical personnel to extract the data.

The survey included patients who were hospitalized in an eligible ward at the time of data collection. One day was considered adequate for each eligible ward to complete the data collection forms. The eligibility criteria included those patients who are $\geq 40$ years of age in eligible medical wards and patients aged $\geq 18$ in eligible surgical wards based on ENDORSE recommendation

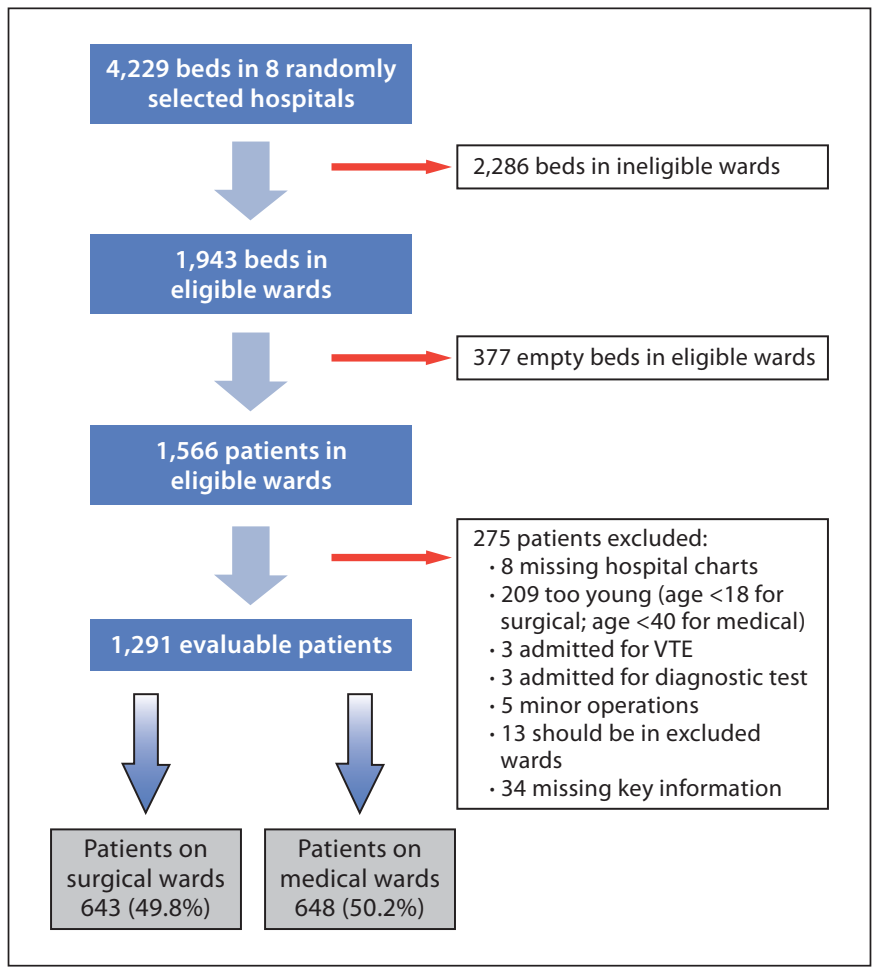

Fig. 1. Selection of the study population.

[14]. In addition, patients assessed for VTE risk included acutely ill medical patients, patients hospitalized for major trauma or undergoing a major surgical procedure requiring general or epidural anaesthesia for at least $45 \mathrm{~min}$. VTE risk assessment in surgical patients was classified as being at highest, high, moderate or low risk for VTE. Data on VTE thromboprophylaxis that had been collected were only those that followed ACCP 2004 guidelines. However, thromboprophylaxis duration could not be assessed due to the cross-sectional nature of the study.

Patients were considered ineligible for VTE thromboprophylaxis if they presented or were at risk of the following: intracranial haemorrhage, liver impairment, bleeding at hospital admission, an active peptic ulcer, and known bleeding disorder. The selection algorithm of eligible patients and the number of the evaluable patients in surgical and medical wards are shown in figure 1.

Statistical analyses of the global ENDORSE report were used in this study [14].

\section{Results}

Of the 1,291 evaluable patients in the 3 countries, 801 (62\%) were considered to be at risk of VTE. Patient characteristics and indications of admission in surgical and medical wards are listed in table 1 . 
Table 1. Characteristics and reasons for hospitalization of eligible patients

\begin{tabular}{|c|c|c|c|c|}
\hline & $\begin{array}{l}\text { Kuwait, } \\
\mathrm{n}(\%)\end{array}$ & $\begin{array}{l}\text { KSA, } \\
\text { n (\%) }\end{array}$ & $\begin{array}{l}\text { UAE, } \\
\text { n (\%) }\end{array}$ & $\begin{array}{l}\text { Total, } \\
\text { n (\%) }\end{array}$ \\
\hline \multicolumn{5}{|l|}{ Patients characteristics } \\
\hline Surgical & $74(27.3)$ & $192(67.6)$ & $125(50.8)$ & $391(48.8)$ \\
\hline Medical & $197(72.7)$ & $92(32.4)$ & $121(49.2)$ & $410(51.2)$ \\
\hline Male & $153(56.5)$ & $209(73.6)$ & $171(69.5)$ & $533(66.5)$ \\
\hline Body mass index (median) & 26.6 & 25.5 & 25.5 & \\
\hline Hospital admission to survey (median), days & 7 & 14 & 5 & \\
\hline \multicolumn{5}{|l|}{ Medical reasons for hospitalization } \\
\hline Acute heart failure (NYHA class III or IV) & $37(13.7)$ & $26(9.2)$ & $37(15.0)$ & $100(12.5)$ \\
\hline Ischaemic stroke & $19(7.0)$ & $20(7.0)$ & $20(8.1)$ & $59(7.3)$ \\
\hline Haemorrhagic stroke & $9(3.3)$ & $4(1.4)$ & $6(2.4)$ & $19(2.4)$ \\
\hline Malignancy (active) & $3(1.1)$ & $5(1.8)$ & $7(2.8)$ & $15(2.3)$ \\
\hline Infection (non-respiratory) & $45(16.6)$ & $32(11.3)$ & $11(4.5)$ & $88(11.0)$ \\
\hline Rheumatologic or inflammatory & $2(0.7)$ & 0 & $13(5.3)$ & $15(2.3)$ \\
\hline Neurologic & $12(4.4)$ & $21(7.4)$ & $18(7.3)$ & $51(6.4)$ \\
\hline Renal & $20(7.4)$ & $18(6.3)$ & $29(11.8)$ & $67(8.4)$ \\
\hline Endocrine/metabolic & $16(5.9)$ & $48(16.9)$ & $76(30.9)$ & $140(17.5)$ \\
\hline GI/hepatobiliary & $16(5.9)$ & $12(4.2)$ & $9(3.7)$ & $37(4.6)$ \\
\hline Other medical condition & $23(8.5)$ & $7(2.5)$ & $45(18.3)$ & $75(9.4)$ \\
\hline \multicolumn{5}{|l|}{ Surgical reasons for hospitalization } \\
\hline Hip replacement & 0 & $5(2.6)$ & $1(0.8)$ & $6(1.5)$ \\
\hline Knee replacement & 0 & 0 & $7(5.6)$ & $7(1.8)$ \\
\hline Hip fracture & 0 & $8(4.2)$ & $5(4.0)$ & $13(3.3)$ \\
\hline Vascular & 3 & $3(1.6)$ & 0 & $6(1.5)$ \\
\hline Thoracic & $1(1.4)$ & $1(0.5)$ & 0 & $2(0.5)$ \\
\hline Gynaecologic & 0 & 0 & $8(6.4)$ & $8(2)$ \\
\hline Other major surgery & $12(16.2)$ & $36(18.8)$ & $27(21.6)$ & $75(19.2)$ \\
\hline Admitted with major trauma but surgery not done & $20(27.0)$ & $77(40.1)$ & $21(16.8)$ & $118(30.2)$ \\
\hline
\end{tabular}

Several VTE risk factors were identified that were present prior to hospital admission, and those acquired during hospitalization. Immobility, cardiac failure and chronic lung disease were the most common risk factors prior to admission, whereas immobilization, intensive care unit/coronary care unit admission and mechanical ventilation were among the common acquired factors during hospitalization (table 2).
The most common contraindication for pharmacological prophylaxis in surgical patients was non-steroidal anti-inflammatory drugs, while in medical patients, it was the use of aspirin and renal impairment. There were also differences in the use of aspirin and non-steroidal anti-inflammatory drugs among the countries. In $\mathrm{Ku}$ wait, aspirin was more commonly used in all admitted patients as compared to the KSA and UAE, whereas non- 
Table 2. Risk factors for VTE prior to and during hospital admission

\begin{tabular}{|c|c|c|c|c|}
\hline & $\begin{array}{l}\text { Kuwait } \\
\mathrm{n}(\%) \\
(\mathrm{n}=271)\end{array}$ & $\begin{array}{l}\text { KSA } \\
\mathrm{n}(\%) \\
(\mathrm{n}=284)\end{array}$ & $\begin{array}{l}\text { UAE } \\
\text { n (\%) } \\
(n=246)\end{array}$ & $\begin{array}{l}\text { Total } \\
\mathrm{n}(\%) \\
(\mathrm{n}=801)\end{array}$ \\
\hline \multicolumn{5}{|l|}{ Conditions present prior to hospital admission } \\
\hline Previous VTE & $5(1.8)$ & $2(0.7)$ & $3(1.2)$ & $10(1.2)$ \\
\hline Thrombophilia (laboratory documented) & 0 & 0 & 0 & $0(0)$ \\
\hline Varicose veins or venous insufficiency & $8(3.0)$ & 0 & 0 & $8(1)$ \\
\hline Postmenopausal hormone replacement therapy & $1(0.4)$ & 0 & 0 & $1(0.1)$ \\
\hline Chronic pulmonary disease & $47(17.3)$ & $17(6.0)$ & $10(4.1)$ & $74(9.2)$ \\
\hline Long-term immobility & $46(17.0)$ & $16(5.6)$ & $21(8.5)$ & $83(10.3)$ \\
\hline Pregnancy (within 3 months) & 0 & 0 & $9(3.7)$ & $9(1.1)$ \\
\hline Obesity (based on physician's note) & $42(15.5)$ & $10(3.5)$ & $14(5.7)$ & $66(8.2)$ \\
\hline Contraceptives & $3(1.1)$ & 0 & 0 & $3(0.3)$ \\
\hline Chronic heart failure & $27(10.0)$ & $22(7.7)$ & $30(12.2)$ & $79(9.8)$ \\
\hline \multicolumn{5}{|l|}{ Additional risk factors for VTE during hospital admission } \\
\hline Admitted to ICU/CCU & $123(45.4)$ & $83(29.2)$ & $70(28.5)$ & $276(34.5)$ \\
\hline Central venous catheter & $67(24.7)$ & $28(9.9)$ & $42(17.1)$ & $137(17.1)$ \\
\hline Mechanical ventilation & $54(19.9)$ & $42(14.8)$ & $67(27.2)$ & $163(20.3)$ \\
\hline Immobile with bathroom privileges & $63(23.2)$ & $23(8.1)$ & $72(29.3)$ & $158(19.7)$ \\
\hline Complete immobilization & $122(45.0)$ & $145(51.1)$ & $145(58.9)$ & $412(51.4)$ \\
\hline Cancer therapy & $1(0.4)$ & $1(0.4)$ & $1(0.4)$ & $3(0.4)$ \\
\hline Heparin-induced thrombocytopenia & $1(0.4)$ & $1(0.4)$ & $1(0.4)$ & $3(0.4)$ \\
\hline
\end{tabular}

$\mathrm{ICU}=$ Intensive care unit; CCU = coronary care unit.

steroidal anti-inflammatory drugs were more commonly used in the KSA as compared to Kuwait and the UAE (table 3).

Pharmacological prophylaxis was the most frequently used method of prophylaxis in surgical and medical patients. Mechanical prophylaxis was a less commonly used method. Graduated compression stockings were the preferred method of mechanical prophylaxis especially in surgical wards (table 4).

Of the 801 patients at risk of VTE, only $322(40.2 \%)$ received ACCP-recommended prophylaxis. The overall use of VTE prophylaxis in high-risk patients in each country and in surgical and medical departments is given in table 5 .

\section{Discussion}

Because only $40.2 \%$ of high-risk patients received ACCP-recommended VTE prophylaxis, VTE prophylaxis was underutilized in the participating centres in the Arabian Gulf region. This finding is lower than approximately $50 \%$ reported in the worldwide utilization of VTE prophylaxis in the ENDORSE study [14]. In addition, there was no significant difference between surgical and medical patients in utilizing VTE prophylaxis because $39.8 \%$ surgical patients and $40.7 \%$ medical patients at high risk received ACCP-recommended prophylaxis in contrast to the global ENDORSE findings reporting that more surgical than medical patients received VTE prophylaxis [14].

When we examine the data more closely by country, the utilization of VTE prophylaxis in the KSA in highrisk medical patients was $62 \%$, higher than in Kuwait (33.5\%) and the UAE (33.1\%). In fact, it is higher than the average global result in medical patients, which was reported as $40 \%$ [14]. On the other hand, more surgical patients at risk of VTE received ACCP-recommended prophylaxis in Kuwait (58.1\%) as compared to the KSA (32.30\%) and UAE (43.2\%). These results seem to indicate that a large proportion of practicing physicians and surgeons in the Arabian Gulf area lack the awareness and knowledge of already published evidence-based guidelines on everyday practice of VTE prophylaxis. It may also indicate the existence of a significant number of patients with contraindications to pharmacologic prophylaxis in this series that lead to hesitancy of health care providers in initiating pharmacologic prophylaxis (ta- 
Table 3. Contraindications to anticoagulation

\begin{tabular}{|c|c|c|c|c|c|c|}
\hline & $\begin{array}{l}\text { Kuwait, } \\
\mathrm{n}(\%) \\
(\mathrm{n}=271)\end{array}$ & $\begin{array}{l}\text { KSA, } \\
\text { n }(\%) \\
(n=284)\end{array}$ & $\begin{array}{l}\text { UAE, } \\
\text { n }(\%) \\
(n=246)\end{array}$ & $\begin{array}{l}\text { All surgical } \\
\text { wards, } \mathrm{n}(\%) \\
(\mathrm{n}=391)\end{array}$ & $\begin{array}{l}\text { All medical } \\
\text { wards, } \mathrm{n}(\%) \\
(\mathrm{n}=410)\end{array}$ & $\begin{array}{l}\text { Total, } \\
\mathrm{n}(\%) \\
(\mathrm{n}=801)\end{array}$ \\
\hline Intracranial haemorrhage & $14(5.2)$ & $15(5.3)$ & $10(4.1)$ & $31(7.9)$ & $8(2)$ & $39(4.9)$ \\
\hline Low platelet count $(<100,000 / \mu \mathrm{l})$ & $9(3.3)$ & $3(1.1)$ & $3(1.2)$ & $6(1.5)$ & $9(2.2)$ & $15(2.3)$ \\
\hline Known bleeding disorder ${ }^{1}$ & 0 & 0 & $3(1.2)$ & $1(0.3)$ & $2(0.5)$ & $3(0.3)$ \\
\hline Bleeding at hospital admission & $7(2.6)$ & $8(2.8)$ & $7(2.8)$ & $12(3)$ & $10(2.4)$ & $22(2.7)$ \\
\hline Active gastroduodenal ulcer & $4(1.5)$ & $3(1.1)$ & $2(0.8)$ & $3(0.8)$ & $6(1.5)$ & $9(1.1)$ \\
\hline Aspirin on admission & $116(42.8)$ & $47(16.5)$ & $73(29.7)$ & $29(7.4)$ & $207(50.5)$ & $236(29.5)$ \\
\hline NSAID on admission (excluding aspirin) & $24(8.9)$ & $57(20.1)$ & $24(9.8)$ & $80(20.4)$ & $25(6.1)$ & $105(13.1)$ \\
\hline
\end{tabular}

NSAID = Nonsteroidal anti-inflammatory drug. ${ }^{1}$ Congenital or acquired.

Table 4. VTE prophylaxis ordered during hospital admission

\begin{tabular}{|c|c|c|c|c|c|c|}
\hline & $\begin{array}{l}\text { Kuwait, } \\
\mathrm{n}(\%) \\
(\mathrm{n}=271)\end{array}$ & $\begin{array}{l}\text { KSA, } \\
\mathrm{n}(\%) \\
(\mathrm{n}=284)\end{array}$ & $\begin{array}{l}\text { UAE, } \\
\text { n (\%) } \\
(n=246)\end{array}$ & $\begin{array}{l}\text { All surgical } \\
\text { wards, } \mathrm{n}(\%) \\
(\mathrm{n}=391)\end{array}$ & $\begin{array}{l}\text { All medical } \\
\text { wards, } \mathrm{n}(\%) \\
(\mathrm{n}=410)\end{array}$ & $\begin{array}{l}\text { Total, } \\
\mathrm{n}(\%) \\
(\mathrm{n}=801)\end{array}$ \\
\hline $\mathrm{UH}$ & $43(15.9)$ & $130(45.8)$ & $9(3.6)$ & $104(26.6)$ & $78(19)$ & $182(22.7)$ \\
\hline VKA & $5(1.8)$ & $2(0.7)$ & $5(2)$ & $4(1)$ & $8(2)$ & $12(1.5)$ \\
\hline Fondaparinux & 0 & 0 & 0 & 0 & 0 & 0 \\
\hline \multicolumn{7}{|c|}{ Mechanical prophylaxis } \\
\hline IPC & $9(3.3)$ & 0 & $10(4.1)$ & $11(2.8)$ & $8(2)$ & $19(2.4)$ \\
\hline Foot pump & 0 & 0 & 0 & 0 & 0 & 0 \\
\hline GCS & $25(9.2)$ & $11(3.9)$ & $9(3.7)$ & $32(8.2)$ & $13(3.2)$ & $45(5.6)$ \\
\hline
\end{tabular}

The IPC, foot pump and GCS were used separately in patients who had contraindications to anticoagulant based on the treating physician's decision. LMWH = Low-molecular-weight heparin; UH = unfractionated heparin; VKA = vitamin K antagonists; IPC = intermittent pneumatic compression; GCS = graduated compression stocking.

Table 5. Proportion of high-risk patients who received VTE prophylaxis according to ACCP guidelines by country and department

\begin{tabular}{lcccc}
\hline & Kuwait, n (\%) & KSA, n (\%) & UAE, n (\%) & Total, n (\%) \\
\hline Prophylaxis according to ACCP & $109(40.2)$ & $119(41.9)$ & $94(38.2)$ & $322(40.2)$ \\
Surgical & $43(58.1)$ & $62(32.3)$ & $54(43.2)$ & $159(40.7)$ \\
Medical & $66(33.5)$ & $57(62.0)$ & $40(33.1)$ & $163(39.8)$ \\
\hline
\end{tabular}


ble 3). Equally important, there was also a lack of unified VTE risk assessment guidelines in the medical centres in the 3 participating Arabian Gulf countries. Thus, regional efforts should be carefully planned to raise awareness among health care professionals through implementation of educational programmes and adoption of mandatory VTE risk stratification charts in the wards.

Unfractionated heparin and low-molecular-weight heparin were the commonest forms of pharmacologic prophylaxis that were used in the Arabian Gulf States (table 4). There was a preference towards unfractionated heparin over low-molecular-weight heparin in KSA hospitals. In addition, unfractionated heparin was the commonly used pharmacologic prophylaxis in the UAE. The preferable use of unfractionated heparin has many possible explanations that include drug availability because of its cheap price, longer experience, and availability of a specific antidote to unfractionated heparin. Graduated compression stocking was used more often than intermittent pneumatic compression because of the limited availability of intermittent pneumatic compression machines on the wards. In addition, foot pumps were never reported to be utilized in the region. The effectiveness of mechanical VTE prophylaxis alone or in combination with pharmacologic prophylaxis has been shown in many studies to be the recommended method in high-risk patients as published in guidelines [12, 16-18]. Mechanical prophylaxis was rarely used in high-risk patients in this study. This underutilization of mechanical prophylaxis supports the notion that more is needed toward raising the awareness of using different forms of VTE prophylaxis when a contraindication to anticoagulants is indicated [17-19].

There are several limitations to this ENDORSE study. Only 8 centres participated in the study and this may not be representative of thromboprophylaxis practices in the other medical centres. The data were obtained from the medical records rather than from direct interview with the patients. Since the ENDORSE study was a cross-sectional study, hence, long-term follow-up on adherence of health care providers to published VTE prophylaxis guidelines was not assessed.

\section{Conclusion}

The findings of the ENDORSE study in the 3 Arabian Gulf States showed that VTE prophylaxis was underutilized in surgical and medical patients at risk of VTE. We therefore recommend that regional efforts should be initiated to raise awareness of VTE risk and ensure that atrisk patients receive appropriate prophylaxis through mandatory hospital-based strategies, and implementation of evidence-based guidelines.

\section{Acknowledgment}

The ENDORSE study was supported through an educational grant by Sanofi (Paris, France).

\section{References}

1 Samama MM, Cohen AT, Darmon JY, Desjardins L, Eldor A, Janbon C, Leizorovicz A, Nguyen H, Olsson CG, Turpie AG, et al: A comparison of enoxaparin with placebo for the prevention of venous thromboembolism in acutely ill medical patients. N Engl J Med 1999;341:793-800.

2 Alikhan R, Spyropoulos AC: Epidemiology of venous thromboembolism in cardiorespiratory and infectious disease. Am J Med 2008;121:935-942.

3 Alikhan R, Peters F, Wilmott R, Cohen AT: Fatal pulmonary embolism in hospitalised patients: a necropsy review. J Clin Pathol 2004;57:1254-1257.

4 Cohen AT, Agnelli G, Anderson FA, Arcelus JI, Bergqvist D, Brecht JG, Greer IA, Heit JA, Hutchinson JL, Kakkar AK, et al: Venous thromboembolism (VTE) in Europe - The number of VTE events and associated morbidity and mortality. Thromb Haemost 2007;98:756-764.

5 Lindblad B, Sternby NH, Bergqvist D: Incidence of venous thromboembolism verified by necropsy over 30 years. BMJ 1991;302: 709-711.

-6 Abdel-Razeq H, Qari M, Kristensen J, Alizeidah H, Al-Sayegh F, Marashi M, Alzeer A, Al-Amoudi O, Qutub H, Al-Humiadi AA, et al: Guidelines for diagnosis and treatment of deep venous thrombosis and pulmonary embolism. Methods Mol Med 2004;93:267-292.

7 Geerts WH, Pineo GF, Heit JA, Bergquist D, Lassen MR, Colwell CW, Ray JG: Prevention of venous thromboembolism: in The Seventh ACCP Conference on Antithrombotic and Thrombolytic Therapy. Chest 2004;126: 338 S-400S.
$>8$ Nicolaides AN, Fareed J, Kakkar AK, Breddin HK, Goldhaber SZ, Hull R, Kakkar VV, Michiels JJ, Myers K, Samama M, et al: Prevention and treatment of venous thromboembolism. International Consensus Statement (guidelines according to scientific evidence). Int Angiol 2006;25:101-161.

-9 Fanikos J: Guidelines and performance measures for the prevention and treatment of venous thromboembolism. J Manag Care Pharm 2008; 14:14S-23S.

10 Hassouna HI: Thrombophilia and hypercoagulability. Med Princ Pract 2009;18:429440.

11 Eikelboom JW, Mazzarol A, Quinlan DJ, Beaver R, Williamson J, Yi Q, Hankey GJ: Thromboprophylaxis practice patterns in two Western Australian teaching hospitals. Haematologica 2004;89:586-593. 
12 Kahn SR, Panju A, Geerts W, Pineo GF, Desjardins L, Turpie AGG, Glezer S, Thabane L, Sebaldt RJ: Multicenter evaluation of the use of venous thromboembolism prophylaxis in acutely ill medical patients in Canada. Thromb Res 2007;119:145-155.

-13 Otero R, Uresandi F, Cayuela A, Blanquer J, Cabezudo MA, De Gregorio MA, Lobo JL, Nauffal D, Oribe M: Use of venous thromboembolism prophylaxis for surgical patients: a multicentre analysis of practice in Spain. Eur J Surg 2001;167:163-167.
14 Cohen AT, Tapson VF, Bergmann JF, Goldhaber SZ, Kakkar AK, Deslandes B, Huang W, Zayaruzny M, Emery L, Anderson FA Jr: Venous thromboembolism risk and prophylaxis in the acute hospital care setting (ENDORSE study): a multinational cross-sectional study. Lancet 2008;371:387-394.

15 Al Sayegh F, Almahmeed W, Al Humood S, Marashi M, Bahr A, Al Mahdi H, Bakir S, Al Farhan M: Global Risk Profile Verification in Patients with Venous Thromboembolism (GRIP VTE) in 5 Gulf countries. Clin Appl Thromb Hemost 2009;15:289-296.

16 Struijk-Mulder MC, Ettema HB, Verheyen CC, Buller HR: Comparing consensus guidelines on thromboprophylaxis in orthopaedic surgery. J Thromb Haemost 2010;8: 678-683.
7 Eppsteiner RW, Shin JJ, Johnson J, van Dam RM: Mechanical compression versus subcutaneous heparin therapy in postoperative and posttrauma patients: a systematic review and meta-analysis. World J Surg 2010;34:1019.

18 Caprini JA: Mechanical methods for thrombosis prophylaxis. Clin Appl Thromb Hemost 2010;16:668-673.

19 Zubkov AY, Wijdicks EF: Deep venous thrombosis prophylaxis in cerebral hemorrhage. Rev Neurol Dis 2009;6:21-25. 